\title{
Evaluation of seismic capacity and response according to the nonlinear modeling approach of members in steel moment frames
}

\author{
Alireza Kian Mehr \\ Master of Civil Engineering, Tarbiat Modares University, \\ Faculty of Civil and Environmental Engineering, Tehran, Iran \\ Alireza.kianmehr@modares.ac.ir
}

\begin{abstract}
In this paper, the aim is to evaluate the seismic behavior of steel momment frames by nonlinear static analysis and incremental dynamic analysis. In this regard, 5 and 10 story frames in both intermediate and special ductility have been used. Since the type of sections and elements used in modeling are among the parameters that affect the behavior of the structure, in this study, which was performed using Opensees software, fiber sections were used for two types of beam elements. Non-linear column (distributed plasticity) and articulated beam element (concentrated plasticity) are used. The results of the analysis show that the ratio of the collapse capacity of the frames to each other varies between $1 \%$ to $6 \%$. On the other hand, by deepening the research on one of the frames, it was shown that the stiffness ratio between the end springs and the middle member will affect the difference between the collapse capacity shown in the analysis.
\end{abstract}

Keywords: momment Frame, Concentrated Plasticity Approach, distributed Plastic Approach, Incremental Dynamic Analysis, Collapse

\section{Introduction}

A catastrophe is an event that is usually "sudden" that causes undesirable changes and changes in objects and creatures that result in disruption of the natural pattern of life. Earthquake is one of these catastrophes and natural disasters. Buildings that according to regulations to Earthquake resistance is designed, it must remain in the linear range due to dead and live gravity due to the use of the building, but due to the occurrence of catastrophic events such as earthquakes can be from the capacity of the structure in the nonlinear range even up to the collapse threshold due to maximum Use possible ground movements, especially for structures with residential use.

If structural members are likely to enter the nonlinear range, a distributed or concentrated approach can generally be chosen for each member. In the extended approach, as the load increases, the internal stresses of each element along the member reach the yield stress, nonlinear expansion along the member occurs through redistribution.
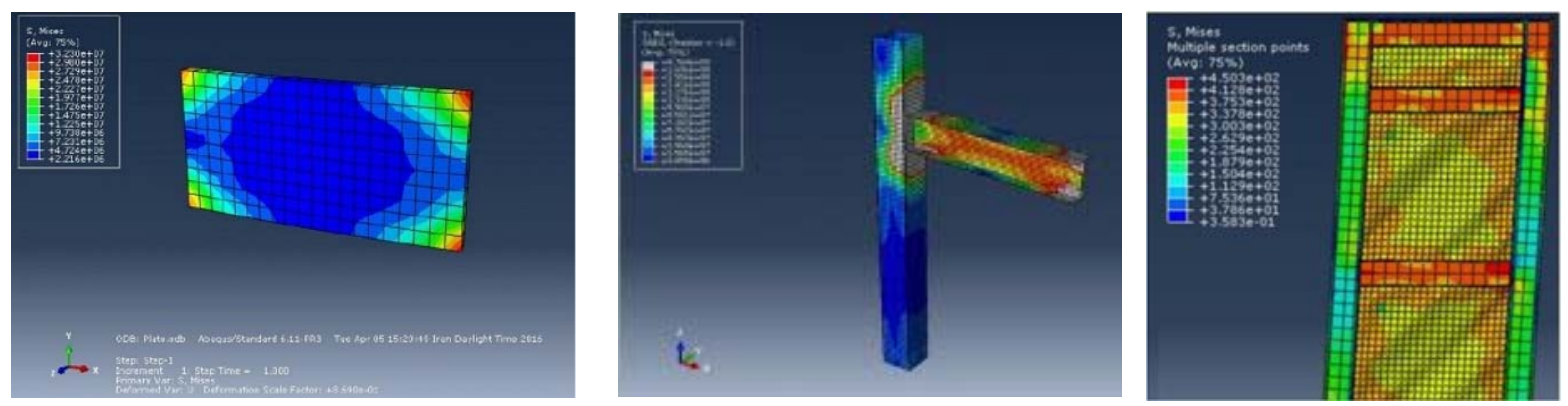

Fig 1:Expansion of plasticity joint length in different structural members

In the concentrated approach, however, by considering a fixed location for zero-length plastic joints, forces and displacements are evaluated according to the tolerable strength of the material, and in other places a linear behavior is assumed for that structural member.

Nonlinear behavior can be modeled with both strain stress equations and displacement forces, or a combination of both approaches. The types of analysis that can be considered are classified according to the appearance of nonlinear behavior in materials (elastic or inelastic) or in the geometry of the members, the most accurate of which is according to Figure 2 non-linear inelastic behavior. [1] 


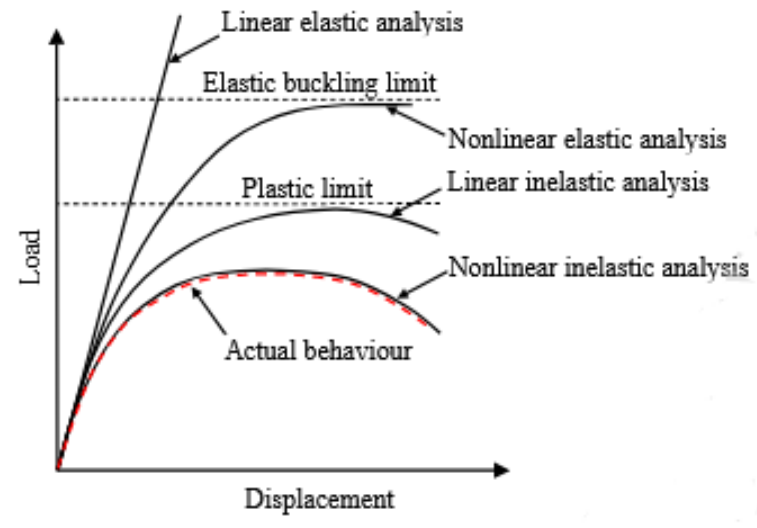

Fig 2:Comparison of nonlinear behavioral curves with different analytical approaches [1]

Behavioral curves can be caused by two types of loading in a model or structural member:

\section{1- Uniform static loading}

2- Cyclic dynamic loading

In cyclic loading, due to the effects of fatigue due to reciprocating loading and residual stresses, the backbone curves or extremes obtained from the response in each loading cycle, as in Figure 3, generally record less stiffness and strength.

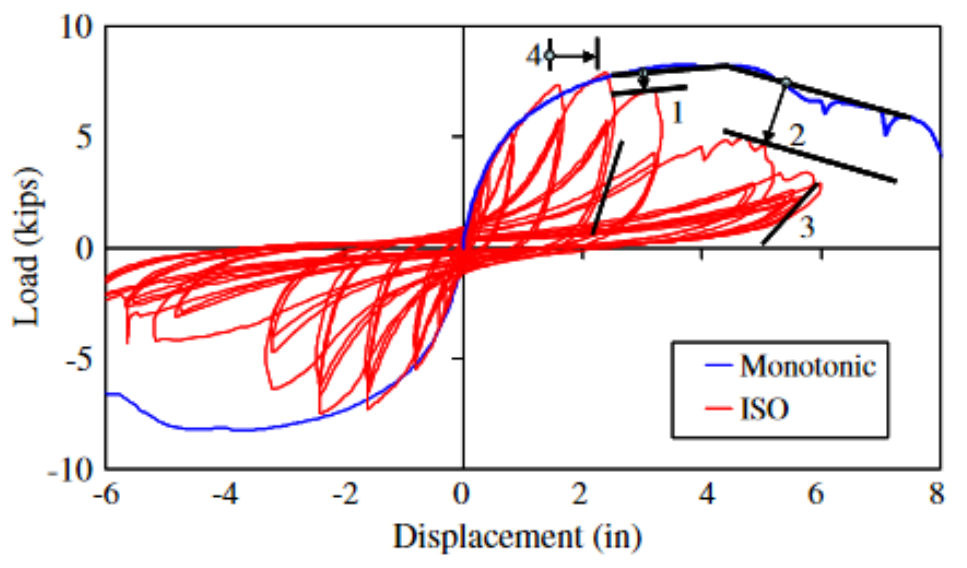

Fig 3:Comparison of behavioral curves with uniform loading and hysteresis loading on a 3ply wood[2]

The first nonlinear model was proposed by Clough and Johnson, including a linear element and an element with a fully plastic elastic behavior [3]. In this model, the deformation of the element depended on the anchor created at both ends. Al-Haddad and White modified the model by changing the location of the plastic joints [6].

In this paper, the aim is to understand the differences in the response of structures according to the type of concentrated or distributed approach, which is followed by the necessary discussions and studies according to the research method.

\section{Methodology}

In this research, using 4 side structural frames taken from the 3D model in Figure (4), the plan of which is taken from the reference [7] with two bays of 5 meters on both sides and three middle bays of 7 meters in the middle of the frame. After designing and analyzing the momment frames based on the tenth topic of the National Building Regulations of Iran(INBR10) and standard 2800 of Iran in ETABS software based on the gravitational load in table (1) and the load combinations in table (2), And its designed sections according to Table (3), they are modeled in OpenSys software, with each of the available approaches for nonlinear modeling of structural members, both concentrated or distributed, ready for the next stages of research. In order to model the mentioned frames in OpenSys software, first the each nodes with the coordinates related to the beginning and end of beams and columns were introduced to the software. These points, as mentioned, will behave in a two-dimensional coordinations with three degrees of freedom, including two degrees of transition and one degree of rotation. 


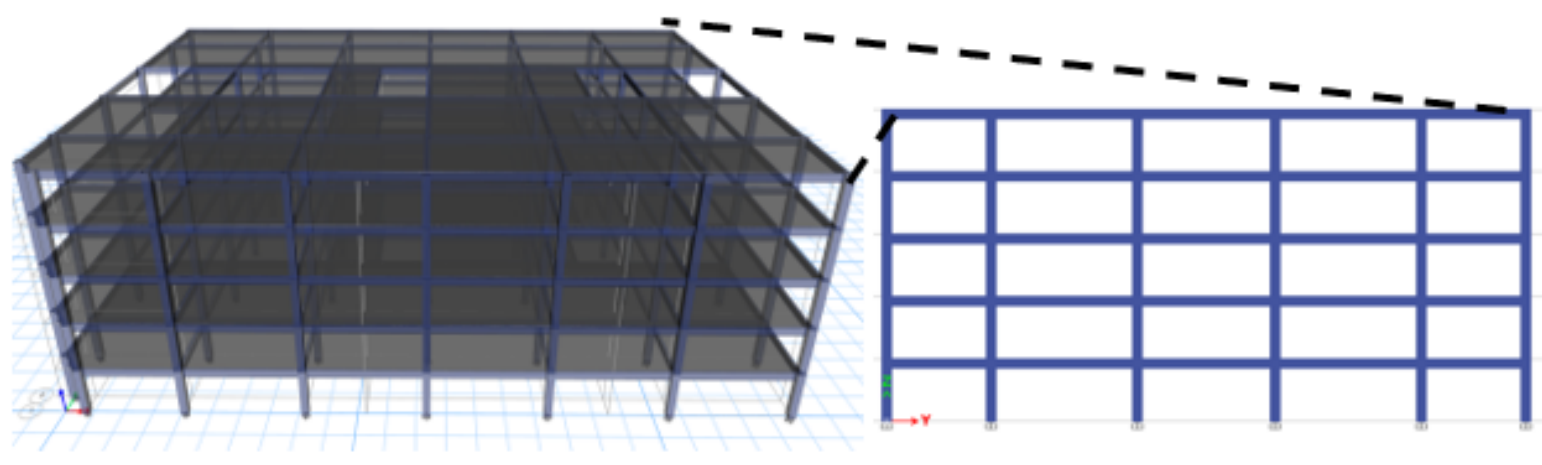

Fig 4:Location of the two-dimensional frame studied in the three-dimensional model of the structure

Table 1:Load rate of models

\begin{tabular}{|c|c|c|}
\hline Load type & Dead load & Live load \\
\hline Floor + slab & $500 \mathrm{~kg} / \mathrm{m}^{2}$ & $200 \mathrm{~kg} / \mathrm{m}^{2}$ \\
\hline
\end{tabular}

Table 2:Analysis and loading details

\begin{tabular}{|c|l|}
\hline Design method & \multicolumn{1}{|c|}{ LRFD } \\
\hline \multirow{2}{*}{ Load combinations } & $1.4 \mathrm{D}$ \\
& $1.25 \mathrm{D}+1.5 \mathrm{~L}$ \\
& $\mathrm{D}+1.2 \mathrm{~L}+1.2 \mathrm{E}$ \\
& $0.85 \mathrm{D}+1.2 \mathrm{E}$ \\
\hline
\end{tabular}

Table 3:Sections of Designed models

\begin{tabular}{|c|c|c|c|c|c|}
\hline \multicolumn{2}{|c|}{ SMF-5 } & \multicolumn{3}{c|}{ IMF-5 } \\
\hline Floors & Column & Beam & Floors & Column & Beam \\
\hline $1-5$ & BOX $450 * 450 * 20$ & IPE 400 & $1-5$ & BOX 450*450*15 & IPE 450 \\
\hline \multicolumn{7}{|c|}{ SMF-10 } & Beam & Floors & Column & Beam \\
\hline Floors & Column & BMF-10 & IPE 550 \\
\hline $1-5$ & BOX 450*450*25 & IPE 550 & $1-5$ & BOX 450*450*20 & IPE 450 \\
\hline $6-10$ & BOX 400*400*20 & IPE 400 & $6-10$ & BOX 400*400*15 & \\
\hline
\end{tabular}

Modeling will be while modeling distributed plasticity with fiber element and modeling concentrated plasticity using zerolength flexural springs at both ends of the beam or column and since the structural members have become two end springs and the middle member in the centralized plasticity approach The energy absorption is not the same in the two parts, so modifications must be made to several arrays of the stiffness matrix of each member, for which a "modellasticbeam $2 \mathrm{~d}$ " member has been used for structural members between plastic joints [8]. This member changes the stiffness matrix at any time by changing the arrays of the stiffness matrix corresponding to each member and considering the degree of division of the total stiffness of each member between the plastic joints and the middle member [9]. Updates the load according to the members' behavioral curve. Considering the ratio of 10 for the stiffness of the end springs to the middle member in the modeled initial frames, finally different ratios are considered to combine the share of each part of the total stiffness of the member, so that the effect of this issue can be investigated in the modeling type. 


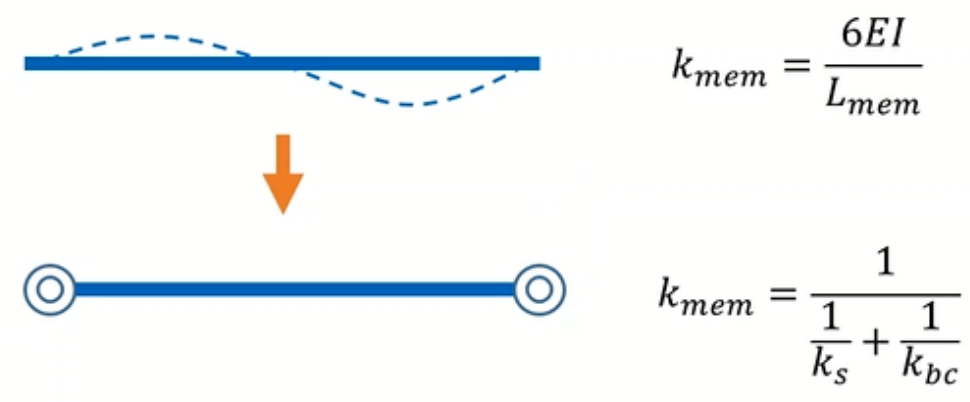

Fig 5:Convert each member to a serial springs

In order to model the behavior of a node with a coordinate in reality in the connection springs as seen in Nodes 3 , 4 and 9 in Figure 6, the shear and axial springs are rigid so that for example the forces in each connection spring are properly from the beam Moved to the column and not absorbed. The momment-rotation curve mentioned in Figure 8 is based on uniform loading, and since the hystertic curve of each member has the cross-sectional geometric characteristics and even the amount and type of loading in the structural model [10], the effect of cyclic decay modes of dynamic earthquake loads by The parameter " $\Lambda$ " and with bilin material is responsible for converting the behavior curve with uniform loading by changing the maximum resistance and the loading resistance to a curve with dynamic cyclic loading such as earthquake to finally the behavioral curve of the members Approach to cyclic in Figure 7. [11,12]

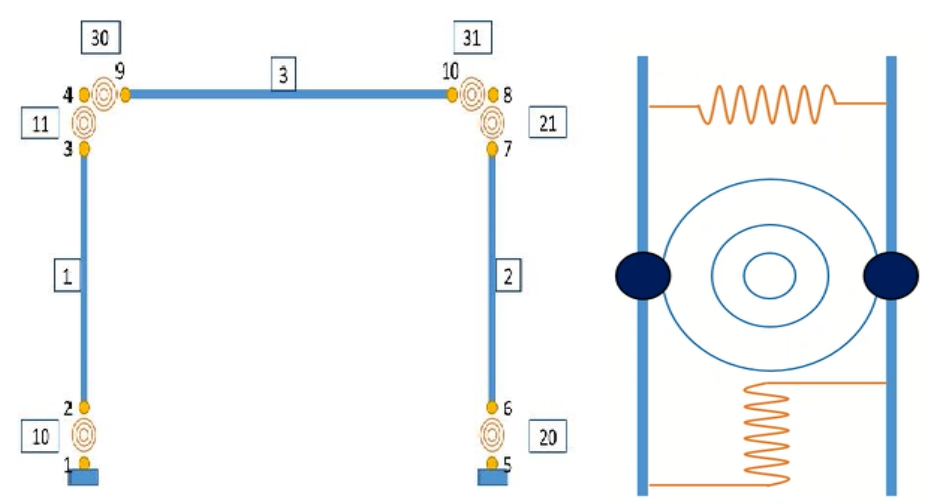

Fig 6:Overview of Zerolength springs and their placement in a single bay momment frame

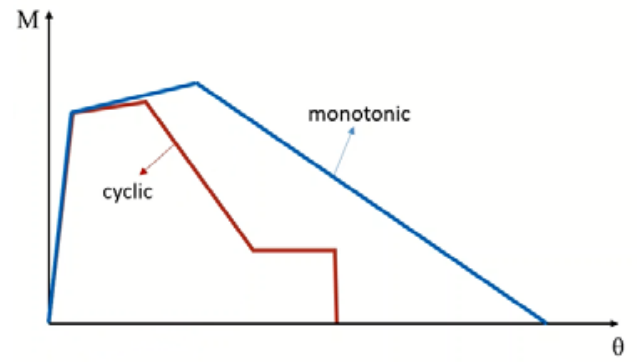

Fig 7:Backbone curve due to uniform and cyclic loading 


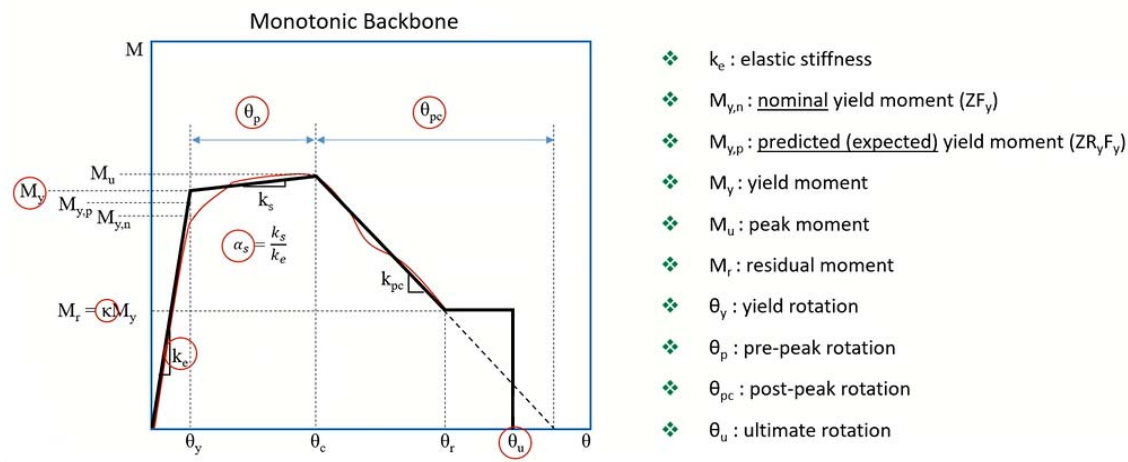

Fig 8:Behavioral curve for uniform loading before applying Landa parameter [13]

The damping of the frames is calculated by assuming its uniform distribution in the whole frame by Rayleigh method and assuming the damping ratio of $5 \%$. Since in this method the damping of the frame is a ratio of the stiffness and mass of the structure, it should be known that the mass of the structure is placed directly on the end nodes. For more accuracy, calculate the seismic mass of the structures from their modeling stage in Etabs by obtaining the ratio of the base shear on the selected two-dimensional frame to the base shear of the threedimensional structure and then multiplying this ratio by the final mass of each floor in the three-dimensional structure. It is obtained that finally the linear mass load obtained for each bay of the two-dimensional frame with respect to the load-bearing spring of each column is transferred to the end node of each column. Finally, through the Rayleigh and region commands, the section proportional to the mass and stiffness of each member of the frame is used for damping calculations in the model.

\section{considering P- $\Delta$ on the models}

In a study, Lignos suggests the use of support columns in this regard [14]. Since this effect has a multiplier effect on the rate of assessment of frame collapse [15] according to Ibara and Krawinkler's research in 2005 [15], this effect should be considered when analyzing frames nonlinearly. For this issue, the idea of leaning columns is used, as described below. Similar to Figure 9 for all frames per floor, through a truss element, the end of the frames under study is connected to the support columns modeled by the "elasticbeamcolumn" command and the ends of the supporting columns are fixed with a hinged support. The resulting virtual frame carries a load of gravity and at the same time does not create additional lateral stiffness. Also, by increasing the stiffness of the columns of the virtual frame, the movement in its vertical direction becomes very small and negligible. In this case, the additional anchor created in the study frame columns during the displacement caused by the earthquake will be due to the P$\Delta$ effect.

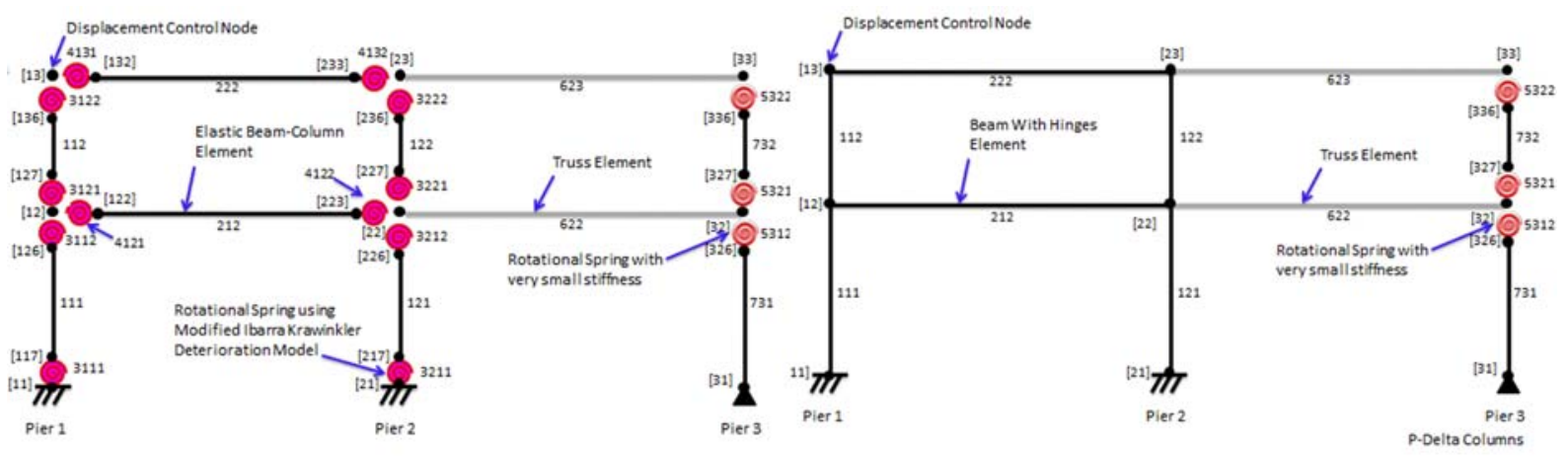

Fig 9:Leaning column modeling method in concentrated approach(left) and distributed(right)

Using selected records from the FEMA-P695 guideline for type D soil in the NEHRP classification according to Table (4), selecting the first earthquake record and its first scale (one tenth more per step) begins the incremental dynamic analysis of the introduced frame. The movements of the frame are recorded by the uniform excitation pattern of its base and the maximum amount of displacement of the frame classes and the acceleration of the corresponding spectrum are recorded as the representative point of this scale from each record and along with the frame response in other scales. The class displacement reaches the limit in the drift criteria, then the algorithm is repeated for each record and the IDA diagrams of each record can be drawn. 
Table 4:Used records

\begin{tabular}{|c|c|c|c|c|c|c|c|}
\hline \multirow{2}{*}{ No } & \multicolumn{3}{|c|}{ Earthquake } & \multicolumn{4}{|c|}{ Station data } \\
\cline { 2 - 8 } & Name & Station & Magnitude & VS_30(m/s) & PGA(g) & $\begin{array}{c}\text { site-source } \\
\text { dist }\end{array}$ & $\begin{array}{c}\text { Field } \\
\text { distance }\end{array}$ \\
\hline 1 & Northridge & Beverly Hills & 6.7 & 356 & 0.52 & 17.2 & Far Field \\
\hline 2 & Northridge & $\begin{array}{c}\text { Canyon } \\
\text { Country-WLC }\end{array}$ & 6.7 & 309 & 0.48 & 12.4 & Far Field \\
\hline 3 & Duzce & Turkey Bolu & 7.1 & 326 & 0.82 & 12 & Far Field \\
\hline 4 & $\begin{array}{c}\text { Imperial } \\
\text { Valley }\end{array}$ & Bonds & 6.5 & 223 & 0.76 & 2.7 & Near Field \\
\hline 5 & $\begin{array}{c}\text { Imperial } \\
\text { Valley }\end{array}$ & Delta & 6.5 & 275 & 0.35 & 22 & Far Field \\
\hline 6 & $\begin{array}{c}\text { Imperial } \\
\text { Valley }\end{array}$ & El Centro & 6.5 & 196 & 0.38 & 12.5 & Far Field \\
\hline 7 & $\begin{array}{c}\text { Imperial } \\
\text { Valley }\end{array}$ & Chihuahua & 6.5 & 275 & 0.28 & 7.3 & Near Field \\
\hline 8 & Kobe & Shin-Osaka & 6.9 & 256 & 0.24 & 19.2 & Far Field \\
\hline 9 & Kocaeli & Duzce & 7.5 & 276 & 0.36 & 15.4 & Far Field \\
\hline 10 & Northridge & Saticoy & 6.7 & 281 & 0.42 & 12.1 & Near Field \\
\hline 11 & Landers & Yermo Fire & 7.3 & 354 & 0.24 & 23.6 & Far Field \\
\hline 12 & Landers & Coolwater & 7.3 & 271 & 0.42 & 19.7 & Far Field \\
\hline 13 & Loma Prieta & Capitola & 6.9 & 289 & 0.53 & 15.2 & Far Field \\
\hline 14 & Loma Prieta & Gilroy & 6.9 & 350 & 0.56 & 12.8 & Far Field \\
\hline 15 & $\begin{array}{c}\text { Kocaeli, } \\
\text { Turkey }\end{array}$ & Yarimca & 7.5 & 297 & 0.31 & 4.8 & Near Field \\
\hline 16 & $\begin{array}{c}\text { Superstition } \\
\text { Hills }\end{array}$ & El Centro & 6.5 & 192 & 0.36 & 18.2 & Far Field \\
\hline 17 & $\begin{array}{c}\text { Superstition } \\
\text { Hills }\end{array}$ & Poe Road & 6.5 & 208 & 0.45 & 11.2 & Far Field \\
\hline 18 & $\begin{array}{c}\text { Cape } \\
\text { Mendocino }\end{array}$ & Rio & 7 & 312 & 0.55 & 14.3 & Far Field \\
\hline 19 & Chi-Chi & CHY101 & 7.6 & 259 & 0.44 & 10 & Far Field \\
\hline 20 & San Fernando & $\begin{array}{c}\text { Hollywood } \\
\text { Stor }\end{array}$ & 6.6 & 316 & 0.21 & 22.8 & Far Field \\
\hline
\end{tabular}

The transfer method is used to determine how the constraint equations are applied in each analysis. In this method, the equations find a relationship between different degrees of freedom. The equation counter and degrees of freedom are RCM type which uses the Reverse Cuthill Mckee algorithm Slowly Storage and solution of the system of equations is SPARCE GENERAL type, which uses the Newmark algorithm with parameters $\beta$ and $\gamma$, respectively 0.25 and 0.5 . The convergence algorithm is Broyden, and the convergence test is performed through the displacement development instruction with an accuracy of $10^{\wedge}(-5)$.

It should be noted that the type of plasticity approach for each frame used in this research is listed in Table (5). In this table, all the frames used are in the form XXX-X-XX, the first three letters representing the intermediate or special ductility, the middle letter indicates the number of stories and the last two letters indicate the type of approach to modeling the plasticity of members, whether distributed (SP) or concentrated (CO). 


\begin{tabular}{|c|c|}
\hline \multicolumn{2}{|c|}{ Model Name } \\
\hline IMF-5-CO & IMF-5-SP \\
IMF-10-CO & IMF-10-SP \\
SMF-5-CO & SMF-5-SP \\
SMF-10-CO & SMF-10-SP \\
\hline
\end{tabular}

In addition, the IMF-5-CO frame has been measured in different classes of stiffness ratio applied to the end springs to the middle member so that the type of structural response in different classes can be measured.

For initial comparison and also verification, through pushover analysis, the response of the intermediate 5 story momment frame in OPENSEES and ETABS software was obtained. This comparison was performed in 3 steps as follows:

1. Nonlinear static response of the whole three-dimensional model in ETABS software and in the north-south direction

2. Nonlinear static response of the studied two-dimensional frame in ETABS software

3. Nonlinear static response of the two-dimensional frame studied in OPENSEES software

The loading pattern of dividing the base shear according to the weight of the floors has been done to push the models by $27 \mathrm{~cm}$. The result of this comparison can be seen for all 3 steps mentioned in Figure 10, also comparing the last two steps separately in Figure 11. A more detailed comparison of these two steps has been drawn. As can be seen, the response of the structure in the two-dimensional frames is close to each other and there is a high difference in the three-dimensional frame. The stiffness of the structure in the lateral direction will be approximately is 7 to 8 times bigger from the stiffness of a frame so This high difference in the surface area below the diagram of the 3D model push curves and the 2D frame seems reasonable. Among the two-dimensional frames according to Figure 11 in the range of linear behavior, the difference is very small and in the range of nonlinear behavior the maximum difference is about $12 \%$ can be due to differences in the definition of nonlinear parameters in the two software. Therefore, the accuracy of modeling of momment frames in two softwares is acceptable and has a good match with structural concepts.

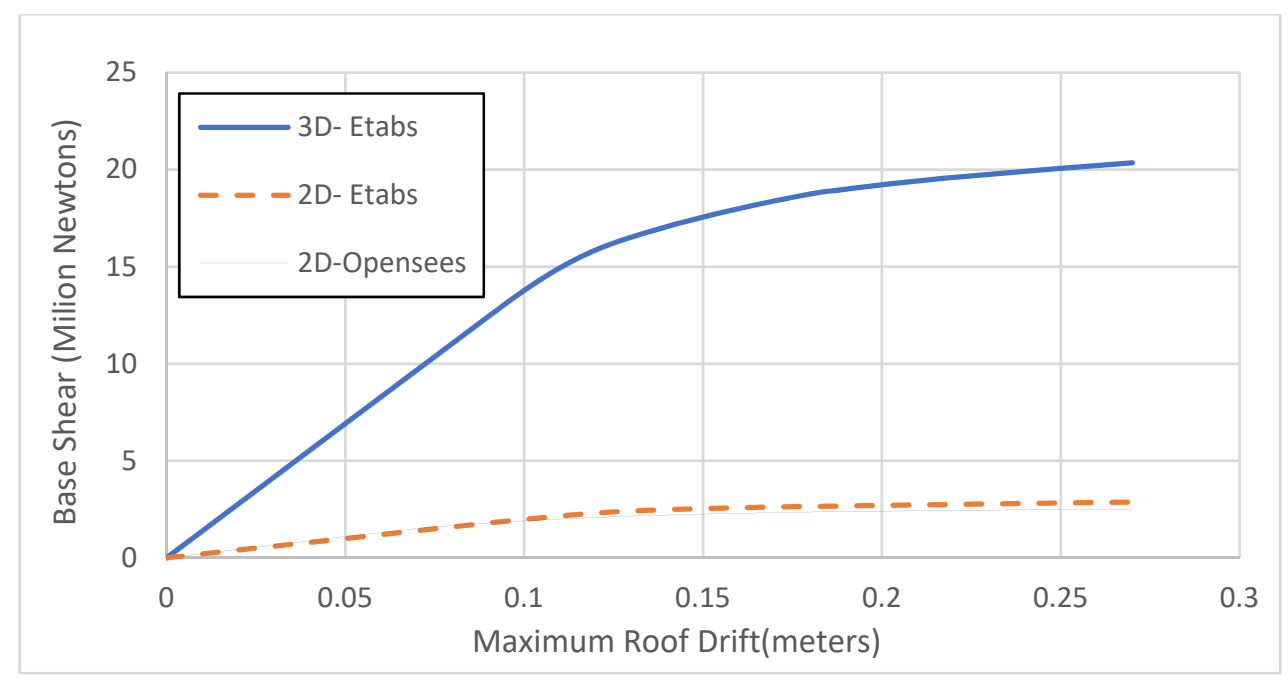

Fig 10:Comparison of push curves of three- and two-dimensional models 


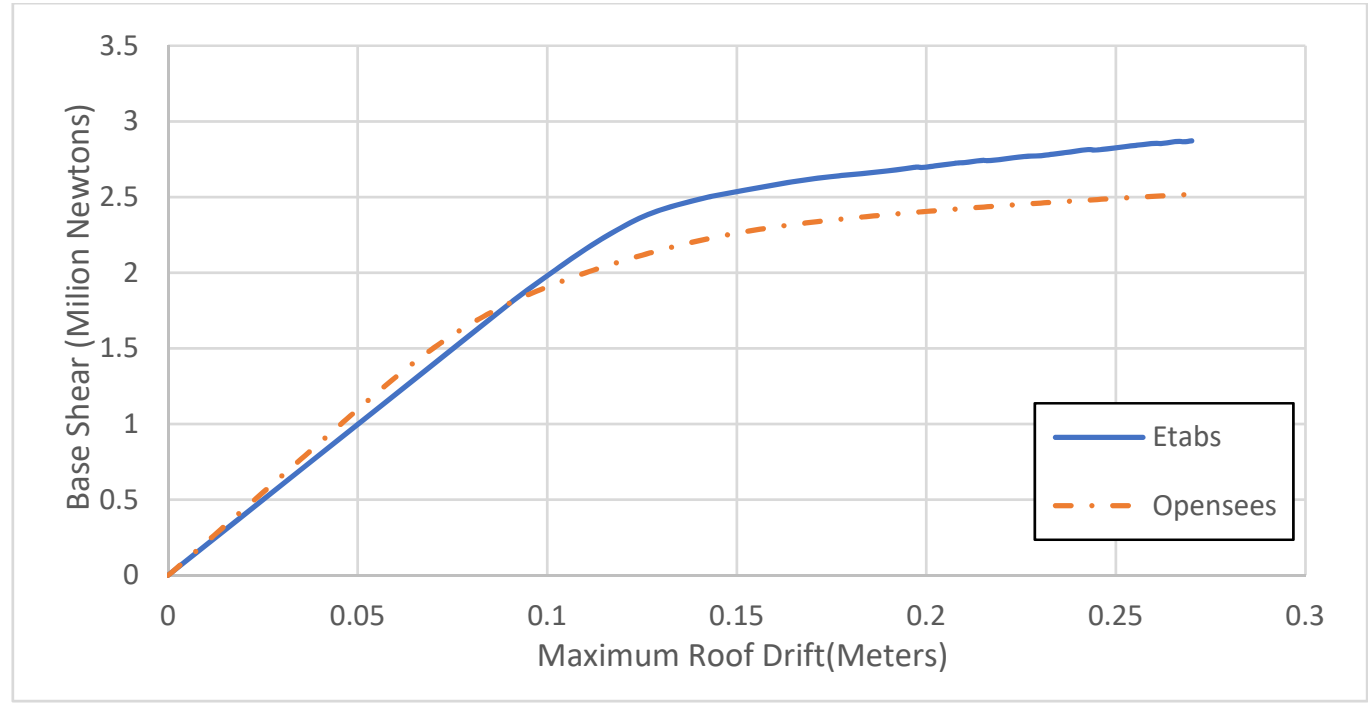

Fig 11:Comparison of the cover curve of two-dimensional models

In addition, a comparison of the nonlinear static response of the structure was performed in two approaches of concentrated and distributed plasticity in OPENSEES software. The results can be seen in Fig 12 and report results with a maximum error of $11 \%$.

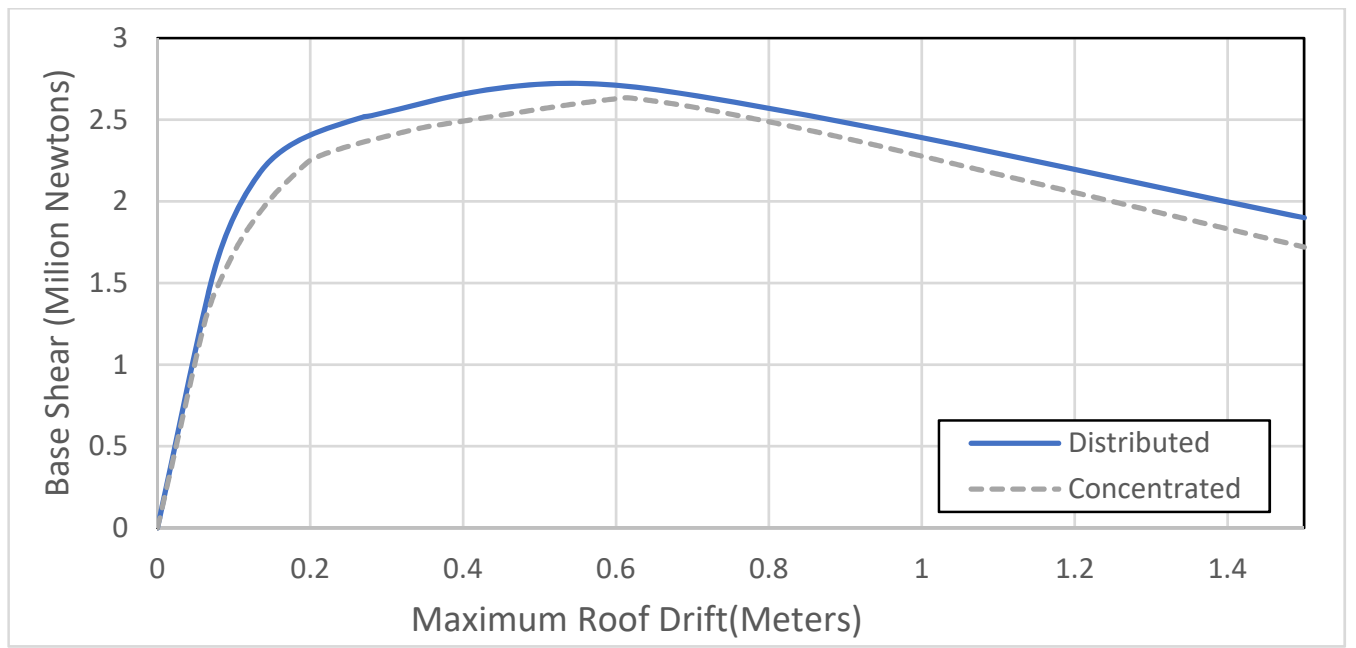

Fig 12:push curve of the two-dimensional models with each approach

\section{Results of incremental dynamic analysis}

The results of IDA analysis obtained from this method along with $16,50,84 \%$ percentiles and the function of Log-Normal Density for IMF-5-CO and SMF-5-CO frames are plotted in Figure 13, in addition to the points due to reduction Hardness relative to $20 \%$ of the elastic stiffness of each diagram is selected for further investigation in these diagrams. To compare the response of incremental dynamic analysis, $50 \%$ percentile curve of each analysis has been used. 


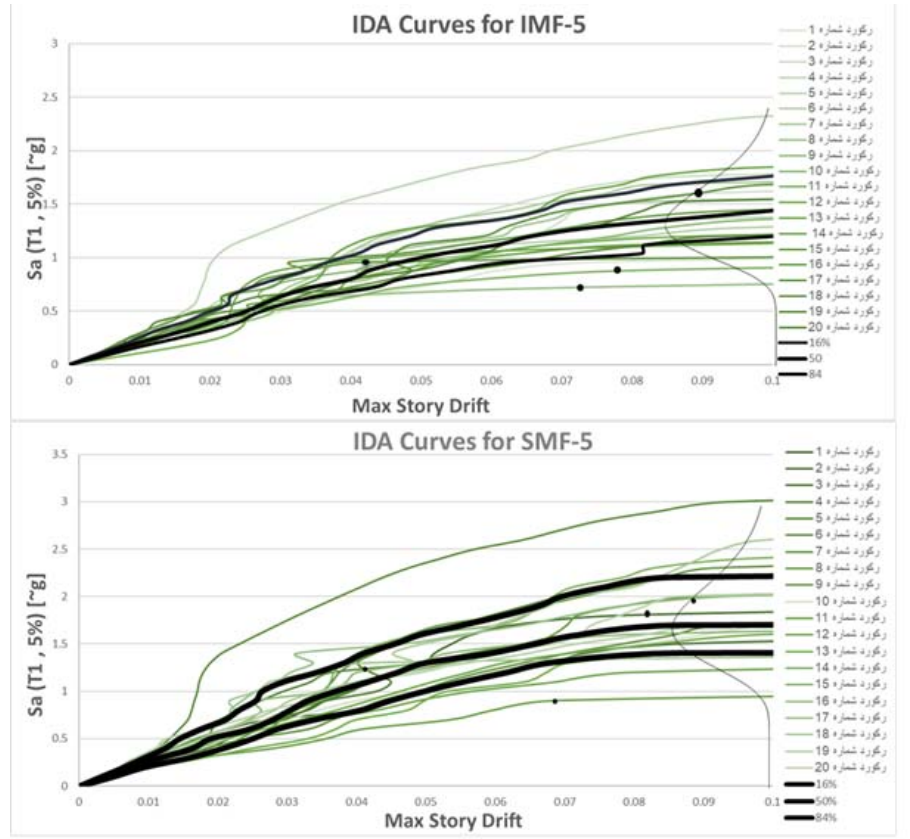

Fig 13: IMF-5-CO and SMF-5-CO IDA curves respectively

In the case of the final performance level of the collapse threshold, we will see a significant reduction in the stiffness and strength of the lateral-resistant force system, a large lateral displacement in the structure. Accordingly, in FEMA350, in momment frames, this limit is set for the IDA curve equal to $20 \%$ of the initial elastic slope or $\theta$ max $=10 \%$. [16] Therefore, the IDA curves are finally drawn to the drift between the maximum $10 \%$. Has been. The difference in response obtained at this drift level for the 50th percentile of IDA curves is shown in Table (6) as shown in Figure 14 [17,18].

Table 6:Comparison of the spectral acceleration ratio in drift $10 \%$ and intersection of curves

\begin{tabular}{|c|c|c|}
\hline Frame & Sa ratio & Intersection \\
\hline IMF-5 & 1.06 & 0.04 \\
\hline IMF-10 & 1.04 & 0.06 \\
\hline SMF-5 & 1.06 & 0.03 \\
\hline SMF-10 & 1.01 & 0.07 \\
\hline
\end{tabular}

Table (6) shows that the design with distributed approach has been able to use more than $8 \%$ of the structural capacity, which has been less in more ductile frames, on the other hand, since the difference starts from the time the first member enters to nonlinear range. And in the frames under study, IDA curve in frames with distributed approach with a slight difference at first lower than frames with concentrated approach, more ductile frames such as special and higher frames, intersection and the beginning of the presence of the curve of distributed frames occur later than concentrated frame curves. The noteworthy point in this case is the approximately uniform response of SMF-10 frames with $99 \%$ accuracy relative to each other in drifts larger than the intersection point, which is due to the high ductility of this frame. This is because the extension of the plastic joint length in the mentioned frame in the range of drifts that is under study and the type of force redistribution is smaller than other frames when entering the nonlinear area. 

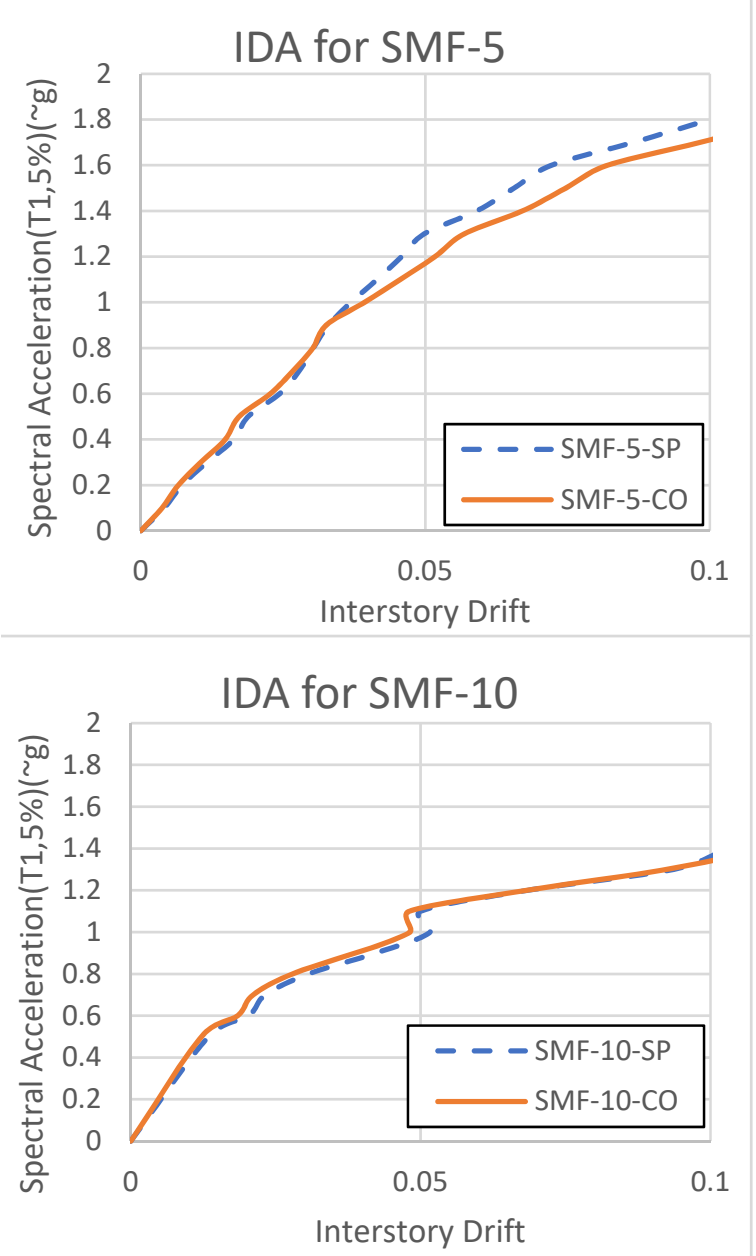

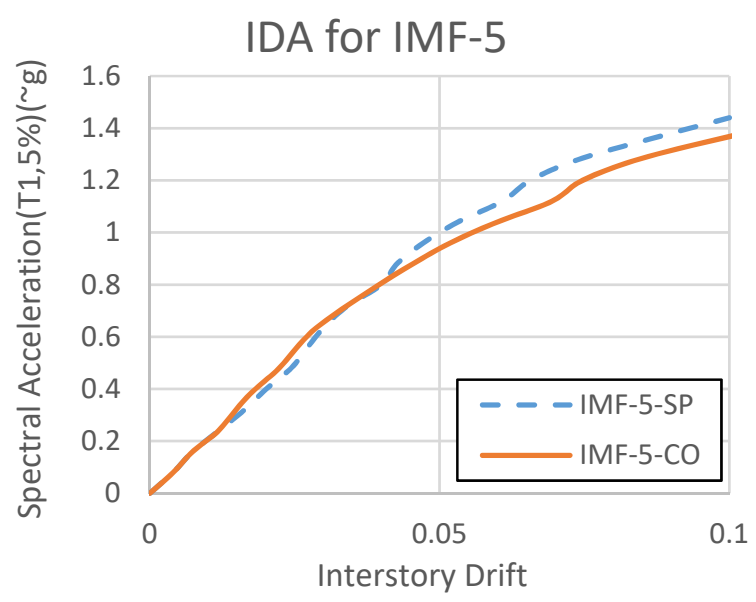

IDA for IMF-10

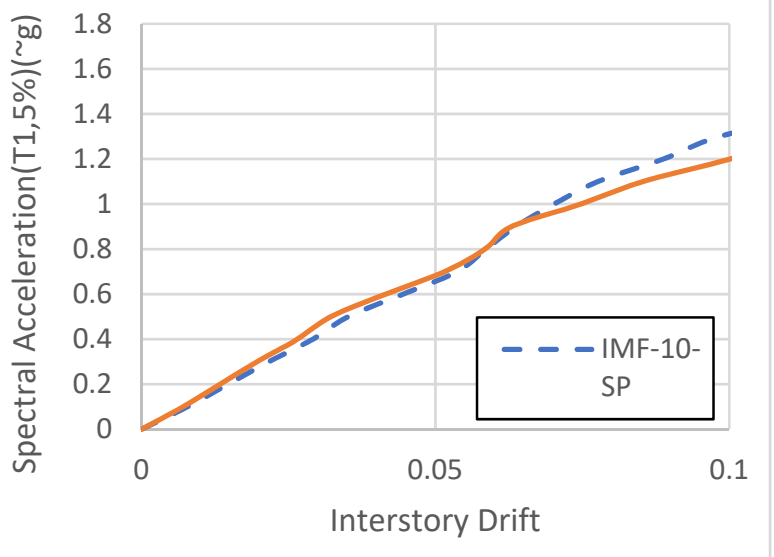

Fig 14:Comparison of 50\% percentile in IDA curve of each frame using different plasticity approach

If different stiffness ratios are used for the end springs to the middle member, for each stiffness ratio, the frames record a different period, in which case the final stiffness of the series springs per member remains constant. For example, in Figure 15, the periodicity obtained for different stiffness ratios is plotted on a semi-logarithmic scale for the IMF-5-CO frame, indicating that for stiffness ratios greater than 100 or less than 0.01 . The periodicity does not differ significantly from the change in stiffness ratios.

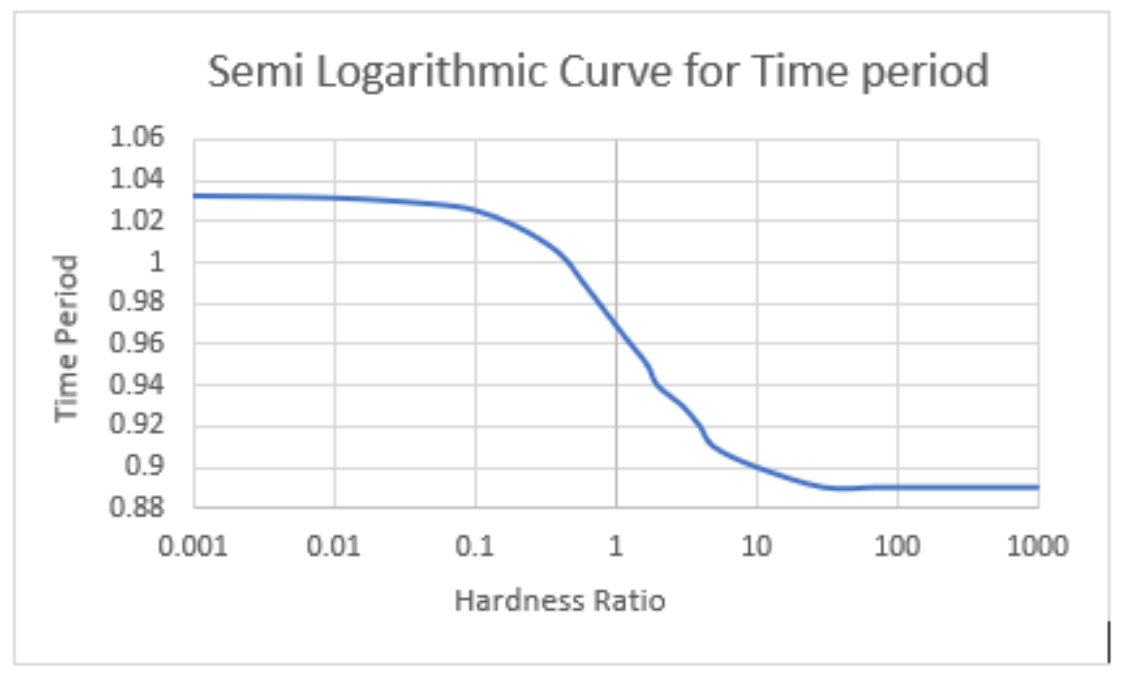

Fig 15:Periodicity change curve for different stiffness ratios of springs to middle member 
In the next step, to deepen the mentioned effect, the corresponding spectral acceleration of drift $10 \%$ for different stiffness ratios is plotted in Figure (16), the amount of this spectral acceleration in the frame is comparable to the broad plasticity approach.

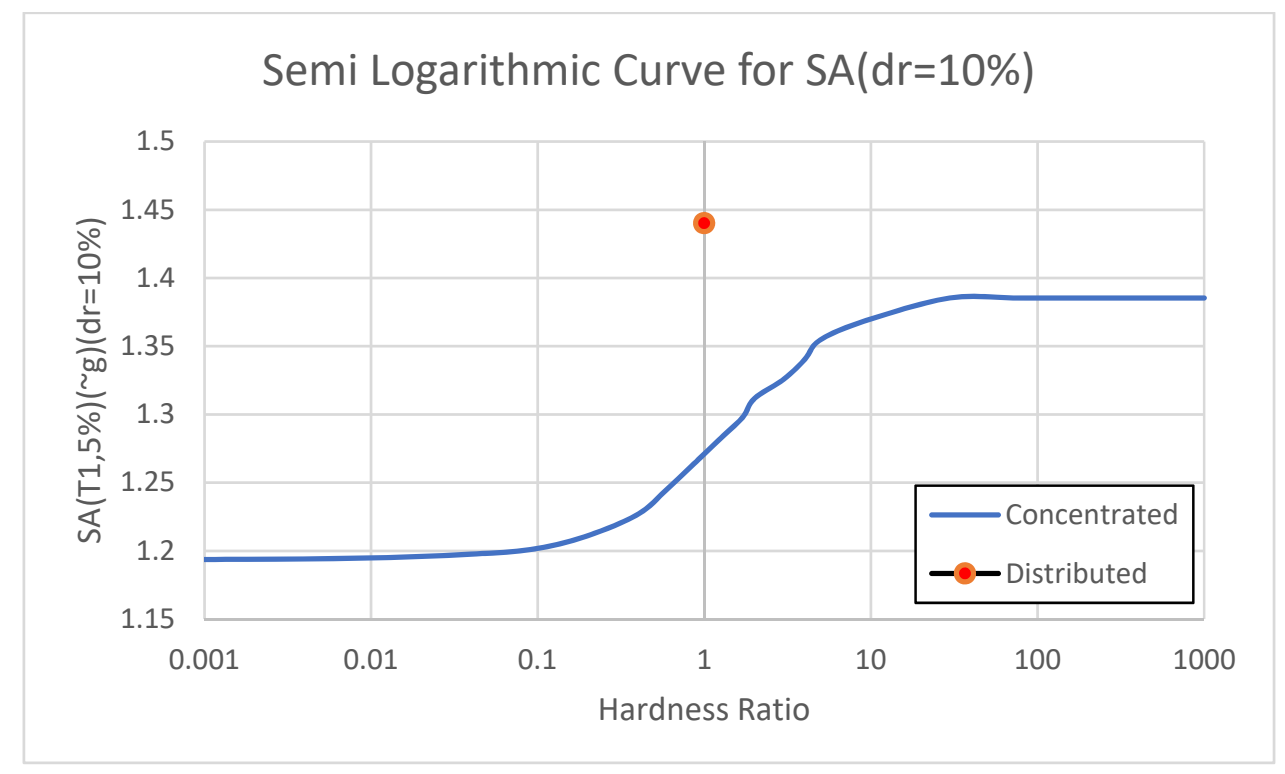

Fig 16:Spectral acceleration corresponding to the collapse threshold for different stiffness ratios

Figure (16) shows that for the frame for different hardness ratios, the spectral acceleration corresponding to the collapse threshold is different and increases with increasing stiffness ratio. On the other hand, considering the above-mentioned figure, since the curve does not change much for hardness ratios higher than 100 or less than 0.01 , by comparing the spectral acceleration of the collapse threshold in the case of distributed plasticity approach, it can be said that The reason for the redistribution effect of this plasticity approach, capacity of the frame in all cases is more than the case of concentrated plasticity.

\section{Results}

- Considering the nonlinear behavior of materials has a significant effect on the structural response. This effect is more visible in dynamic analysis. Concentrated and distributed plasticity methods are widely used to model the nonlinear behavior of materials. In this study, nonlinear static analysis and incremental dynamic analysis of 4 steel momment frames were performed considering the behavior of concentrated and distributed plasticity. The results of these modelings show that the approaches considered for modeling the nonlinear behavior of steel elements have an almost similar response in terms of maximum response structural drift. In general, the spectral acceleration ratio of the collapse threshold in the two approaches is 1 to $6 \%$, which is less in more ductile frames as the intersection of the two IDA curves occurs in larger drifts.

- In the next step, to deepen the results for one of the frames modeled with concentrated springs, free dynamic vibration analysis was performed for different stiffness ratios between the end springs and their middle member. The results show that by increasing the stiffness ratio in While the total stiffness remains constant, the periodicity decreases in the range of 0.01 to 100 and the spectral acceleration of the collapse threshold increases and remains constant for other values. It was also found that the collapse capacity in the modeling mode with a distributed approach will be shown more than in all hardness cases in modeling frames with a concentrated approach.

\section{References}

[1] Huu-Tai Thaiet al. Review of nonlinear analysis and modelling of steel and composite structures, International Journal of Structural Stability and Dynamics, 2020

[2] Ibarra LF, Medina RA, Krawinkler H. Hysteretic models that incorporate strength and stiffness deterioration. Earthquake engineering \& structural dynamics. 2005

[3] Clough RW, Johnston SB "Effect of stiffness degradation on earthquake ductility Requirements", In Transactions of Japan earthquake engineering symposium, Tokyo, pp. 195-8, 1966.

[4] Giberson MF, "The response of nonlinear multi-story structures subjected to earthquake excitation", Ph.D. Dissertation, California Institute of Technology, Pasadena, CA, 1976.

[5] Giberson MF, "Two nonlinear beams with definitions of ductility", J Struct Div, Vol. 95(2),1969

[6] Spacone E, Filippou FC, Taucer FF, "Fibre beam-column model for non-linear analysis of RC frames: Part I: Formulation", Earthquake Engineering and Structural Dynamics, Vol. 25, pp.711-725, 1996.

[7] Hinduabadi, R ,, Probabilistic analysis of seismic performance of hospitals. Thesis of Tarbiat Modares University, 2017 
[8] Zareian, Farzin, and Ricardo A. Medina. "A practical method for proper modeling of structural damping in inelastic plane structural systems." Computers \& structures 2010: 45-53.

[9] Zareian, Farzin, and Helmut Krawinkler. Simplified Performance-Based Earthquake Engineering. , 2006.

[10] Ibarra LF, Medina RA, Krawinkler H. Hysteretic models that incorporate strength and stiffness deterioration. Earthquake engineering \& structural dynamics. 2005 Oct;34(12):1489-511.

[11] Lignos DG, Hartloper AR, Elkady A, Deierlein GG, Hamburger R. Proposed updates to the ASCE 41 nonlinear modeling parameters for wide-flange steel columns in support of performance-based seismic engineering. Journal of Structural Engineering. 2019 Sep 1;145(9):04019083.

[12] NIST, "Guidelines for Nonlinear Structural Analysis for Design of Buildings",Report no.2017b

[13] Lignos DG, Krawinkler H. "Sidesway collapse of deteriorating structural systems under seismic excitations." Rep. No. TR 172, John A. Blume Earthquake Engineering Research Center. 2009.

[14] H. Krawinkler, F. Zareian, D. G. Lignos, and L. F. Ibarra, "Prediction of collapse of structures under earthquake excitations," in Proceedings of the 2nd International Conference on Computational Methods in Structural Dynamics and Earthquake Engineering (COMPDYN 2009), Rhodes, Greece, CD-ROM paper, paper no. CD449, 2009, pp. 22-24.

[15] Ibarra, LF and Krawinkler, H.. Global Collapse of Frame Structures under Seismic Excitations. John A. Blume Earthquake Engineering Center Technical Report 152. Stanford Digital Repository,2005.

[16] Federal Emergency Management Agency," Recommended Seismic Design Criteria for New Steel Moment-Frame Buildings". Report No. FEMA-350, Federal Emergency Management Agency, Washington, DC,2000.

[17] Vamvatsikos, D. and Cornell, C.A. "Incremental Dynamic Analysis. s.l.": Earthquake Engineering and Structural Dynamics, pp. 491514,2002

[18] Vamvatsikos, Dimitrios \& Cornell, C. The incremental dynamic analysis and its application to performance-based earthquake engineering. 2002. 